\title{
PULMONARY FINDINGS ON HIGH RESOLUTION COMPUTED TOMOGRAPHY IN PATIENTS WITH JUVENILE DERMATOMYOSITIS: RETROSPECTIVE STUDY
}

\author{
CARLA HELENA CAPPELLO (UNICAMP, CAMPINAS, SP, Brasil), EDUARDO BRONZATTO (UNICAMP, \\ CAMPINAS, SP, Brasil), ROBERTO MARINI (UNICAMP, CAMPINAS, SP, Brasil), SERGIO DERTKIGIL \\ (UNICAMP, CAMPINAS, SP, Brasil), SIMONE APPENZELLER (UNICAMP, CAMPINAS, SP, Brasil)
}

\section{BACKGROUND}

Juvenile Dermatomyositis (JDM), are complex, heterogeneous, autoimmune diseases that affect skeletal muscles and the skin. The interstitial lung disease (ILD) is a complication that has been observed in 20$78 \%$ of patients and can be a determining prognosis, causing greater morbidity and mortality. Objective: to evaluate the finds pulmonary by high-resolution Computerized Tomography (HRCT) in accompanying patients in outpatient pediatric rheumatology unit.

\section{MATERIALS AND METHODS}

Retrospective study of 62 patients diagnosed with JDM, which are submitted to the examination of image for clinical monitoring of the disease. TCAR tests were observed in approximately 10 years, including repeated CT scans assessed: interstitial pneumopatia; pneumomediastium; the presence of nodules; opacity in ground glass; fibros elastic stretch marks; septal thickening; bronquica wall thickening. Two patients were excluded because they had overlap with systemic lupus erythematosus.

\section{RESULTS}

HRCT was retrieved for analysis in 62 of patients. We observed interstitial pneumopatia in 9 (14.51\%), showed; nodules/micronodules in 20 (32.25\%), opacity in ground glass in $21(33.87 \%)$, fibroatelectasias in $13(20.96 \%)$, septal thickening in $7(11.29 \%)$, bronchial wall thickening in $10(16.12 \%)$ and pneumomediastium in 1 (1.61\%). Findings were observed during the first 2 years of disease In 62 patients.

\section{CONCLUSION}

We conclude that pulmonary involvement in the diseases presented above has been more evident and that high resolution computed tomography provides additional information to clinical evaluation. 